\title{
COMPLEXIDADE DA COMUNICAÇÃO MEDIÁTICA
}

\author{
MANUEl José LOPES DA Silva*
}

\section{Introdução}

1. A descoberta das ondas de rádio e o surgimento da TSF originaram uma forma de comunicação directa e imediata que alterou o relacionamento entre a anterior comunicação social (a Imprensa) e a Sociedade. As transformações socio-económicas resultantes da guerra de 14/18 foram reforçadas com as emissōes de rádio que, rapidamente, se generalizaram por todo o mundo. Veio a seguir a TV. Â aceleração do processo comunicativo corresponde, por isso, uma aceleração das referidas transformações, estando tudo nas origens da própria guerra de 39/45. A comunicação passou a ser objecto de investigaçōes que foram revelando a complexidade dos seus efeitos, nos vários domínios da psicologia social, da sociologia, da economia e da teoria política.

Fala-se agora em crise da comunicação política, efectivamente existente, que, naturalmente, está associada, numa relação circular de causa/efeito/causa, a uma crise da própria sociedade individualista de massa.

Factos psico-sociais como a teledependência, a insensibilização dos utentes, o seu empobrecimento cultural e desequilíbrio psicológico, foramse acentuando e culminam no fechar do homem sobre si próprio, produzido pelos Media identitários como a Internet. No domínio socio-económico, deve referir-se o aumento das diferenças sociais, já de si preocupante, mas

* Universidade Nova de Lisboa. 
sobretudo o fenómeno da marginalização, mesmo da exclusão social que aflige as nossas sociedades.

No domínio político, onde a crise é mais evidente, à instantaneidade e superficialidade da informação junta-se agora uma preocupante hipermediatização que acentua cada vez mais a deslegitimação dos protagonistas e das instituições políticas.

A Sociedade da Informação, culminância e emblema de todo este complexo processo, padece ela própria das vulnerabilidades de uma sociedade que aceitou como referência a mentalidade pós-moderna, que é apenas uma tentativa de recuperação de uma ilustração falhada.

\section{Aceleração do processo comunicativo}

1. O surgimento da comunicação de massa usando ondas electromagnéticas, evento designado por TSF, deu-se no começo do séc. XX e representou, efectivamente, uma mudança de natureza relativamente à anterior comunicação de massa, baseada na imprensa. A partir daí, inicia-se um processo de aceleração da comunicação que não tem sido suficientemente estudado e que está a chegar, nos nossos dias, a um ponto culminante que tem os seus perigos.

A Rádio popularizou-se, de facto, com os programas de actualidade, as transmissões de jogos desportivos, de comícios políticos, de grandes cerimónias nacionais, e isto tanto nos EUA como na Europa. Pouco depois, surge a utilização deste medium pelos grandes manipuladores de massa, como Hitler e Lenin, o que tem sido objecto de numerosos estudos, atribuindo à personalidade destes homens a mobilização das massas. No entanto, tal não seria possível sem as massas terem o sentimento de instantaneidade, de estarem a viver o mesmo momento do líder que fala.

Quando a TV se torna um MCM (Meio de Comunicação de Massa), com J.L.Baird, nos anos 20, é justamente por tornar acessível ao público londrino, "em directo", as corridas de cavalos de Ascot. Os primeiros tempos da TV na Europa foram de preocupação com a informação, o divertimento e a cultura das massas. Como os processos de informação/conhecimento e de aculturação exigem uma elaboração pessoal e tempo para ela (de facto todos sabemos que informação não é igual a conhecimento), a questão do simultâneo/diferido não era de facto importante.

Quando, porém, em 1953, os franceses puderam assistir pela TV, em directo, à coroação da rainha Isabel de Inglaterra iniciou-se um interesse crescente da sociedade por este tipo de programas, designados na altura por «exteriores». O desenvolvimento tecnologico deu-se no sentido de tornar possível a satisfação desse interesse, primeiro pelo desenvolvimento espectacular das interligações por micro-ondas, que permitiram a estru- 
turação das grandes «networks» americanas, depois com a TV Cabo e, mais tarde, com a TV Satélite.

A Internet, surgida entretanto, resultou da convergência entre os computadores e as comunicações e assegura, noutra modalidade, o acesso directo e instantâneo ao local do correspondente ou a uma base de dados, revelando que se deu, entretanto, a abolição de fronteiras entre os media tradicionais, progressivamente integrados em redes que veiculam texto, som e imagens sob a forma digital. A CNN da TV Cabo/Satélite é o exemplo mais claro do triunfo do directo quer na guerra, quer no escândalo político.

A aceleração do tempo transforma bruscamente a experiência humana, por inscrever no mesmo ritmo de acontecimentos sociedades muito afastadas espacial e culturalmente. O ideal do jornalista, consistindo no desejo de reduzir ao mínimo o tempo de fornecimento da informação, está a realizar-se, mas à custa, sabemo-lo agora, de certas limitações fundamentais. De facto, a transmissão instantânea anula toda a possibilidade de verificação (impossível a contrastação das fontes), obriga o comentador a ser simples relator, a ter de fazer um comentário instantâneo, sem qualquer perspectiva, a quente, a ter de emitir hipóteses imprudentes ou sem pertinência. O sentimento de insegurança, de instabilidade que daqui resulta, estende-se aos sistemas económico, social e político, provocando uma crise que estudaremos mais adiante.

A aceleração da comunicação é paralela à sua globalização, provocada pela própria evolução do tardo-capitalismo ou neo-liberalismo. Estamos, porém, muito longe da ubiquidade sonhada em 1878 por Adriano de Paiva, em que a globalização da comunicação não é devida à universalização dos valores culturais, mas sim a razões económicas.

Estas características da comunicação mediática não só não atenuaram as disfunçōes já conhecidas dos anos 50 e sistematizadas por Lazarsfeld e Merton, como, infelizmente, as reforçam e suscitam outras. Assim, por exemplo, a Internet, apresentada como um meio interactivo que permite o acesso a uma rede mundial e oferecendo novas possibilidades de convivência virtual, na realidade fecha os utentes sobre si próprios, negando-lhes a espontaneidade da comunicaçāo directa e a afirmação de uma verdadeira identidade, favorecida pela intersubjectividade. O diálogo com um computador, obviamente, não é igual ao diálogo directo com outra pessoa.

A convergência entre Computadores e Comunicações a que nos referimos é simultânea da convergência com a Indústria de Conteúdos, criando a chamada Convergência 3C. A evolução actual desta tripla convergência evidencia, todavia, um desequilíbrio preocupante, devido à debilidade da Industria AV (a dos Conteúdos) face às outras duas. 


\section{Complexidade psico-social}

3. A multiplicidade dos media oferecidas aos utentes recorre a uma complexa estrutura de redes, o que, cada vez mais, lhes exige adestramentos especiais e permanente adaptação individual. Naturalmente que cada medium de comunicação tem a sua especificidade própria de influenciar o destinatário; a rádio não tem os mesmos recursos da TV, a imprensa é diferente da Internet.

Uma análise estruturo-funcional do complexo sistema global dos media contemporâneos seria sempre trabalhosa e levaria, provavelmente, a identificar mais as suas diferenças que as semelhanças. Em contrapartida, a análise tecnológica, muito própria da Teoria da Complexidade, permite uma fácil identificação das finalidades que, desde há já 40 anos, lhe têm sido atribuídas e que o caracterizam mais completamente.

Duas finalidades desde sempre atribuídas aos media da nossa sociedade, a promoção da integração social e da asserção pessoal, são hoje reconhecidamente afectadas de modo negativo. A integração social regride para a atracção social dos anos 20 , com as telenovelas e a informação espectáculo, e a asserção pessoal degenera nas conversas-espectáculo e espectáculos-realidade que, em vez de promoverem o diálogo entre as pessoas, as reduzem ao nível de puros objectos da curiosidade malsã de certos utentes da comunicação.

Outras duas finalidades complementares dos MCS, a transmissão da herança cultural e a estabilização da mudança social, que sempre esperámos poderem contribuir para a promoção da sociedade, são postas literalmente em causa, devido à filosofia monetarista dos canais comerciais.

Têm sido também identificados efeitos resultantes da massificação que se detecta em todos eles, dado que a generalização do mercado e o crescimento da Indústria Cultural a ele associada levaram à adopção de processos cognitivos que antes se não aplicavam. Tais processos são utilizados para obter a "fidelização» dos utentes aos vários meios, baseando-se em acções de captação/memorização/motivação de temas como enredos de telenovelas, marcas de um produto ou sigla de um partido, com vista à aquisição do produto, ou ao sentido de voto num partido, ou simplesmente à adesão ao canal.

$O$ esforço de captação/memorização tem-se acentuado, tanto mais quanto mais se verifica a volatilização das audiências devido ao "zapping», ou pura e simplesmente devido à saturação e insensibilização, tão frequentemente verificados. Se, nos anos 50 , os sociólogos da comunicação referiam já a insensibilização, como um dos efeitos negativos no plano psico-social e político, já a teledepedência, associada ao desequilíbrio psicológico, adquire hoje maior expressão, e o empobrecimento cultural, 
também por eles referido, é hoje um problema extremamente preocupante da sociedade de consumo.

Finalmente, os meios identitários, transitivos, propondo, como vimos, a inserção dos utentes em redes conviviais (virtuais), na realidade acabam por fechar os utentes sobre si próprios, reduzindo-os a puros dialogantes com máquinas, com o horizonte de actuação fechado sobre programas muito constringentes.

A multiplicação de canais e a diversidade de redes parecem promover o surgimento da opulência comunicacional, anunciada por Abraham Moles. Mas, na realidade, tal não acontece, devido à escassez dos conteúdos veiculados pelos canais que, longe de assegurarem uma oferta diversificada, propõem antes conteúdos que se repetem monotonamente. De resto, a própria lógica da concorrência comercial em TV obriga os programadores a oferecerem nos diferentes canais, à mesma hora, programas da mesma índole.

É neste domínio que se verifica a maior demonstração da falta de respeito dos programadores da TV pelos utentes. A estes não é proporcionada verdadeira liberdade de escolha. Na realidade, são constrangidos, condicionados a manterem-se agarrados sempre ao mesmo canal.

\section{Complexidade socio-económica}

4. O domínio socio-económico da comunicação é, na Europa, dominado pela agitada transição do Serviço Público Monopolista para um Sistema Comercial concorrencial, o que se repercute em múltiplos e nevrálgicos domínios, com a criação de graves problemas, ainda muito longe de serem ultrapassados.

Ao Serviço Público associa-se a ideia de responsabilidade pública ou social, enquanto que aos operadores comerciais se reconhece e aceita apenas a necessidade de maximização dos lucros. A filosofia da programação comercial assenta na necessidade de fidelizar o público, orientando-se exclusivamente pelos índices de audiência. Estes são simples «ratios» comerciais, de índole estatística e impessoal, em ligação com a programação de "fluxo", mas sem qualquer relação com a qualidade dos programas.

Se, com a programação de fluxo, se pretende corresponder às expectativas dos consumidores, essas são as que se situam ao nível das emoções saciáveis com o mau gosto, ódio, violência e sexo, porque são mais fáceis de satisfazer, como Mander demonstrou, há já algum tempo. Infelizmente, são as que mais determinam a massificação dos utentes, no sentido de tenderem a entorpecer a sua actividade intelectual e impedir a sua afirmação, como pessoas e como cidadãos. Começa-se hoje a considerar que 
o próprio exercício da cidadania democrática é fortemente contrariado pela programação à base de telenovelas, futebol e concursos.

A base de sustentação do sistema é a publicidade que, hoje, é fortemente agressiva e é uma das variáveis importantes da excessiva propensão para o consumo, o que começa a afligir algumas sociedades europeias, como a portuguesa. A estimulação parece ser excessiva, dada a diminuição dos volumes de poupança a nível nacional.

Existe um Código de Publicidade com algumas restrições aos conteúdos que não são respeitadas, como aliás sucede em relação a Lei da TV, também ela abrangendo todos os operadores.

Mas é no universo dos utentes da comunicação que se está a gerar uma situação de extrema injustiça, reflexo, aliás, da dinâmica cega do neo-liberalismo contemporâneo. Assim como o sistema actual de economia global está a gerar um número cada vez maior de marginalizados, quer entre Norte e Sul, quer no Norte ou só no Sul, também o número de pessoas com capacidade para aceder aos Novos Meios de Comunicação (NMC), é uma percentagem cada vez menor do total da população.

Reconhece-se hoje que só um Serviço Público à altura de uma missão nacional poderá contrariar estas tendências preocupantes. É necessário que este serviço esteja presente não só na TV e Rádio convencionais, como também em todos os outros meios que venham a ser oferecidos ao público. Só a sua lógica de responsabilidade social poderá contrabalançar a programação de fluxo generalista, ou as ofertas de serviços personalizados degradantes.

5. São cada vez mais manifestas as expectativas generalizadas por uma nova ordem da Economia. Ultrapassadas as utopias dos sistemas económicos de direcção central, resta-nos a solução da economia de mercado. Mas as injustiças sociais que ela gera, como as do séc. XIX, que originaram a chamada questão social, estão na realidade a despertar as consciências de um número cada vez maior de académicos e decisores socio-económicos.

Começam a surgir documentos oficiais e contribuições pessoais, clamando pelo estabelecimento de consignas sociais no funcionamento da economia de mercado, tendentes a defender os direitos das camadas de menor capacidade económica. No campo da comunicação, só o Serviço Público pode defender tais direitos, como temos vindo a assinalar.

Há na actual Indústria da Comunicação uma lógica que é incompatível com a elevação do nível cultural das massas. Este foi o ideal que esteve na origem do desenvolvimento da Imprensa, no séc. XIX, e da Rádio e da TV, no séc. $\mathrm{XX}$, mas foi abandonado. $\mathrm{E}$ esta preocupação abrangia uma razão política que era a da democratização da sociedade.

Massificada a sociedade pelo consumismo, satisfeita a curiosidade das massas com a informaçāo-espectáculo, futebol, concursos e telenovelas, é 
duvidoso que se possa esperar uma consciencialização política e social, exigindo a participação do cidadão nas decisões que o afectam. Consideramos sensatas e dignas de consideração as apreensões que Konrad Lorenz manifesta a Karl Popper, num diálogo clássico que todos conhecemos.

\section{Crise da comunicação política}

6. É já antiga a tradição de encarar a Comunicação Social como um instrumento fundamental para a democratização da sociedade. Os investigadores e profissionais americanos invocam, ainda hoje, com frequência, a $1 .^{\text {a }}$ Emenda à Constituição dos EUA, mas na Europa a luta pela liberdade de expressão no século passado também deixou profundas raízes. Ainda hoje, muitos intervenientes no diálogo socio-político em Portugal invocam a Lei da Rolha, do século passado, e a censura do salazarismo, como exemplos de processos com que certos políticos combateram a democracia.

A expressão acessível da pluralidade de opiniões tem sido considerada fundamental, para que o cidadão, no uso de uma razão considerada esclarecida, fizesse as suas escolhas sensatas acerca da sociedade que desejava. O tipo de informação que hoje domina os media, em que predomina a política espectáculo, se não ilude estas expectativas, pelo menos frusta-as grandemente. Há uma enorme erosão das figuras dos políticos de todos os quadrantes, o que tem como consequência imediata a sua deslegimitação. Mas é o próprio sistema político que é afinal posto em causa, como demonstrou o exemplo recente dos inquéritos judiciais feitos a membros do Parlamento.

Os investigadores da aérea crítica insistem no carácter sistémico desta crise de legitimidade do tardo-capitalismo, que é evidente, e todos os dias é reforçada com novos escândalos veiculados pelos media.

Outros investigadores da área liberal acreditam que, apesar de tudo, ainda há razões para esperança e que o retorno aos ideais ilustrados poderia recuperar os Novos Meios de Comunicação para a causa democrática (Wolton).

Não partilhamos nem do pessimismo dos críticos, nem do optimismo dos liberais. Acreditamos que a sociedade civil, constituída por pessoas inteligentes e livres, tem capacidade para superar as actuais ameaças que lhe são feitas pela lógica do Mercado. Mas também reconhecemos que a actual manipulação das massas atinge os níveis de "violação psíquica» que referia Jacques Ellul.

Há que retomar, por isso, a convivência com os grandes ideais e valores da nossa tradição clássica e regressar a um novo humanismo realista que substitua a proposta da Ilustração que falhou, segundo os críticos, mas 
que a pós-modernidade, que é a Ilustração prosseguida por outras vias, afinal tenta recuperar.

7. O renascimento cultural, tão necessário, é claramente dificultado com as tendências que anteriormente referimos para a informação superficial e instantânea. Nada de mais contrário à informação objectiva, fiel e reflectida, necessária, à elaboração do pensamento político e a opções profundas do cidadão, ao nível das avaliações éticas.

Mas não é só o Parlamento, gerador de Leis e directrizes fundamentais para a sociedade, que não tem capacidade de reflexão e espaço de manobra, tão necessários à complexidade do mundo actual, e isto para já não falar no desgastante conflito com o Poder Judicial. É, sobretudo, o Executivo que evidencia incapacidade para a elaboração de estratégias para o longo prazo, devido à pressão permanente dos media e da opinião pública.

\section{Um sistema vulnerável}

8. Blumler e Gurevitch, por um lado, e Wolton, por outro, levaram a cabo investigações sobre a comunicação política que, pela sua convergência, constituem um único quadro conceptual de referência sobre tal matéria. Ambas partem da perda de legitimidade dos políticos, extremamente preocupante nas nossas sociedades, e, através da análise minuciosa do funcionamento dos sistemas mediático e político, equacionam os problemas postos pela actual situação.

O sistema da comunicação política é constituído pela instituições políticas, as instituiçōes mediáticas e as expectativas da audiência (opinião pública). Este sistema é, por sua vez, um sub-sistema do sistema político, a quem compete a pilotagem da sociedade, tarefa que, actualmente, se tornou numa acção complexa,"como temos vindo a sublinhar.

A comunicação política não reflecte pura e simplesmente o conflito estabelecido entre os actores políticos convencionais (governo, partidos, assembleias, altas magistraturas), mas é também suscitado pela própria actividade dos media e pelas reacções da opinião pública.

A capacidade de intervenção dos média é expressa pelo modo pelo qual eles são capazes de restruturar o tempo e o carácter dos acontecimentos políticos (congressos, comícios, intervenções dos lideres, etc.); de definir as situações de crise a que os políticos são obrigados a reagir; de solicitar comentários sobre questões que os profissionais dos media considerem importantes; de injectar novas personalidades no diálogo político (como por exemplo os moderadores de TV); e de estimular o crescimento de novas empresas de comunicação (de relações públicas, de inquéritos de opinião, de propaganda política, de especialistas de imagem). Ainda que tais formas 
de intervenção possam não ser bem acolhidas por alguns políticos, a índole normativa do poder dos media pode ser crucial em tempos de crise.

O fundamento da credibilidade que ainda se concede aos MCS está na expectativa acerca do papel dos seus órgãos especializados, na defesa dos cidadãos contra possíveis abusos da autoridade política, o que pressupõe também a sua independência face às forças em confronto. Naturalmente que se não contempla, neste momento, o tipo de programação massificante, constituída por telenovelas, concursos, futebol, conversas-espectáculo, realidades-espectáculo, que se destinam simplesmente à diversão do público e à sua fidelização aos canais.

9. A estrutura da audiência dos media tem sido objecto de sucessivas investigações, mas não é possível apresentá-la numa forma compreensível e útil, dada a multiplicidade dos factores que para ela contribuem, muitos deles radicando-se em níveis psicológicos profundos, em zonas do subconsciente.

No entanto, é possível identificar alguns papéis complementares dos actores do sistema político. Assim, à expectativa do Partidário na Audiência, correspondem o Guia Editorial nos Media e a figura do Combatente nos Políticos. À expectativa do Cidadão liberal na Audiência, correspondem as figuras do Moderador nos Media e do Argumentador Racional dos Políticos. À expectativa do Monitor na Audiência, correspondem o "Cão-de-Guarda» nos Media e o Fornecedor de Informação nos Políticos. E à figura do Espectador na Audiência, correspondem a de Animador nos Media e a de Actor nos Políticos.

Este paradigma funcional ajuda a compreender o tipo de ligações que se estabelece entre os elementos do sistema da comunicação política. Assim, a integração dos elementos no sistema depende do grau de interrelaçōes entre os níveis, da adopção, pelos participantes no processo comum de comunicação, de orientações equivalentes, de modo a poderem intervir todos em sintonia.

O distanciamento entre os actores, ou seja entre a audiência e os media, por um lado, e entre o eleitorado e o sistema político, por outro, pode ser avaliado pelo grau de correspondência entre os papéis da audiência e os papéis dos media e dos líderes políticos. $\mathbf{E}$ a influência cruzada entre os vários actores deve basear-se em critérios de equilíbrio de influências e de moderação política. Se um sistema de media se baseia, por exemplo, num alto grau de autonomia política, ela permite aos profissionais da comunicação uma considerável liberdade para adoptar diferentes orientaçôes e comportamentos.

No caso em que os objectivos de Serviço Público prevalecem nas organizações dos media, as funções de "cão-de-guarda" são preferidas pelos profissionais dos media e os membros da audiência são estimulados a 
assumir o papel de Vigilante («monitor role»). Quando são os partidos políticos a controlar os media, o papel de Combatente é adoptado pelos políticos, o de Guia Editorial pelos media e a audiência é pressionada a adoptar o papel de Partidário.

Se, finalmente, os media são governados por objectivos autoritários e paternalistas, dois casos se podem dar. A audiência tenderá a seguir os media, evoluindo para os papéis de Partidário ou de Monitor; ou as expectativas da audiência entrarão em conflito com as orientações e as mensagens dos emissores e tenderão a evitar a informação política, desconfiarão dos media e sentir-se-ão alienados da política.

10. As relações entre os vários actores do sistema, porém, nem sempre são regidas por critérios de equilíbrio e moderação. Frequentes vezes, as relaçōes desestabilizam-se e surgem situações que prejudicam gravemente quer a imagem dos políticos perante a sociedade, quer a imagem dos próprios media.

Uma das características que, por vezes, deforma a comunicação política é a hipermediatização, ou seja, uma excessiva exposição pública, seja dos políticos, seja dos comunicadores. Quando tal acontece, há uma descredibilização dos protagonistas perante os cidadãos, que afecta a própria vivência política e que, quando instalada, tem consequências funestas para o voto dos cidadãos.

Porém, não é só a abstenção que é preocupante. O próprio diálogo socio-político empobrece e a sociedade pode passar a uma fase de desencanto e de alheamento que deslegitima o regime, como há já algum tempo referiu Habermas.

Esta confrontação directa entre os media e a sociedade é pouco saudável, porque pode dar lugar a excessos da parte dos primeiros. A nossa sociedade individualista de massa é muito sensível aos valores complementares de Liberdade e Igualdade para os cidadãos. Se os media fazem um mau uso da sua liberdade de expressão, filtrando a informação segundo maus critérios que os levem a pôr de parte temas importantes considerados incomodativos, mais tarde ou mais cedo a sociedade mostrará sinais de rejeição.

Esta situação, que é imprópria da sociedade aberta, proposta aos cidadãos como ideal a atingir pelo regime político, poderá ser corrigida pela actuação de sistemas intermédios que ajudem a sociedade a tornar-se mais consciente. Como diz Wolton, as nossas sociedades necessitam hoje mais de "mediação» do que de "mediatização». Exemplos de tais «mediadores» são as associações cívicas de toda a natureza, cuja importância num regime democrático tem sido mal avaliada. Tais organizações podem, inclusivamente, criar no diálogo social um espaço de reflexão e de recuo face à informação instantânea, que ajude os cidadãos a organizarem-se cognitivamente 
e a passarem da captação da informação para a elaboração pessoal e para o conhecimento, que é o pressuposto de uma actuação democrática.

\section{A sociedade da informação}

11. O conceito de Sociedade da Informação tem surgido associado à progressiva generalização dos sistemas de comunicação e dos computadores a toda a sociedade. É um conceito originariamente tecnicoeconómico, que reflecte o objectivo final do mercado da comunicação, dirigido já não a toda a sociedade nacional, mas a todo o espaço geopolítico mundial.

Porém, à medida que uma tão grande multiplicidade de canais é oferecida aos utentes, duas grandes carências se vão tornando mais evidentes. A primeira carência, a dos Conteúdos que alimentem tantos canais, parece revelar a falta de criatividade dos Sistemas de Produção, seguramente devida nāo a razões pessoais, mas certamente a razões sistémicas. Na realidade, não é crível que a espécie humana esteja a perder qualidades que anteriormente se revelavam em circunstâncias diferentes.

A grande racionalização da produção, causada por perspectivas monetaristas, é certamente um dos constrangimentos à criatividade, mas haverá certamente outros, por exemplo a tendência para ignorar a nossa riquíssima tradição cultural, onde tantos temas poderiam dar origem a produções de grande interesse.

A segunda carência é talvez mais grave, porque traduz a aceitação de uma grave injustiça social. Ela resulta directamente da lógica monetarista que está a comandar a introdução de novos canais, como é o caso da TV digital, e que se orienta para estratos muito especializados da sociedade, minoritários, deixando de lado grandes domínios da população sem capacidade económica.

A possibilidade que os computadores oferecem de criação de imagens artificiais, «imagens de síntese», e a utilização da Internet para aceder a «locais» de convivência electrónica têm proporcionado a alguns espíritos especulativos o ensejo de falar no surgimento de um novo mundo "virtual», de uma nova convivência não com pessoas reais, mas com entidades artificiais.

$\mathrm{Na}$ realidade, é incorrecto falar em novas formas de convivialidade electrónica, já que o utilizador do computador continua a fechar-se cada vez mais sobre o teclado, o que é equivalente a fechar-se sobre si próprio.

Por estas e outras razões, Wolton propõe que, na utilização dos actuais e dos NMC, se guardem distâncias, ou seja, que se faça uma avaliação ponderada sobre as vantagens e inconvenientes que cada vez se tornam 
mais evidentes e que se avance conjugando cinco verbos: distinguir, regulamentar, relativizar, retardar e revalorizar.

Distinguir primeiro entre inovação científica e inovação técnica, que nem sempre andam a par e passo, como mostra a implementação dos sistemas de fibra óptica, que não justificam de todo a euforia inicial. Depois, há que distinguir entre descoberta, aplicação e serviços. Os industriais do sector apresentam sempre uma perspectiva optimista, esquecendose de referir que as expectativas da sociedade nem sempre correspondem aos desejos, particularmente na assinatura de novos serviços. Outra distinção importante é entre áreas potenciais de utilização, referindo-se o trabalho à distância, os serviços, a educação, o lazer, todos ao mesmo nível. No entanto, é evidente que o acesso destas diferentes áreas às Tecnologias da Informação tem tido temporizações diferentes e intensidades diferentes, não correspondendo, em geral, às expectativas criadas.

No domínio da regulamentação, há que, decididamente, corrigir certos abusos do mercado, que tende a nivelar tudo e todos ao mais baixo nível, como é o caso da concorrência entre canais de TV. Há permanentes abusos em todas as categorias de programas, desde a informação à ficção, desde as conversas-espectáculo aos filmes.

O prejuízo que tal concorrência está a causar à sociedade, em termos de massificação e de insensibilização, é incalculável. Há que repor o respeito pelos direitos dos utentes. A relativização das perspectivas de abordagem dos NMC começa por constatar que as NTIC não resolvem melhor a relação indivíduo/massa que os media de massa. Antes pelo contrário, o vínculo social que a TV generalista ainda assegura é claramente posto em causa com os meios personalizados, como já afirmámos.

As NTIC, com efeito, não contribuem em nada para a integração cultural, uma vez que elas usam a mesma linguagem que os media convencionais e pertencem à mesma cultura. Nada de novo portanto, circunstância que nos deve levar a considerar as muitas prospectivas que se fazem sobre a sociedade da abundância de canais, como extremamente falível.

Mas retardar é também importante. Quantas vezes teremos sentido como que uma vertigem perante a aceleração dos processos de inovação, bastando recordar o que se passa com a potência e os programas dos computadores, o que nos obriga a trocar de modelo, quando o que possuímos ainda funciona satisfatoriamente... Além do mais, são situações que afectam a nossa economia pessoal e tantas vezes desnecessariamente em termos negativos.

Por último, a revalorização pode não implicar a adopção de critérios saudosistas. No entanto, reconhecemo-lo há comportamentos que temos desvalorizado injustamente, e que só temos vantagem em recuperar. De resto, a perspectiva sistémica, na sequência da biológica, recorda que o 
comportamento normal dos sistemas pressupõe um ajustamento equilibrado entre herança cultural e mudança/adaptação às novas circunstâncias.

12. O mundo virtual a que as NTIC permitem aceder representa uma das aquisições da humanidade reclamada pela designada pós-modernidade. Daniel Inneraritv afirma a este propósito que o acordo secreto entre filosofia pós-moderna e sociedade da informação, para desmaterializar o mundo, transformando-o em imagens, signos e representaçōes, anulou tendencialmente a diferença entre realidade e ficção.

Toda a vida social é afectada pela nova situação e, particularmente, a vida política. À medida que avançam as possibilidades técnicas de comunicação, confirma-se o temor ante a possibilidade de que aumente também a impotência ante o engano e a simulação. A vida política passa a estar submetida a uma progressiva teatralização. Os seus pilares são a comunicação e a gestão económica e o seu destino é transformar-se em espectáculo.

Do princípio liberal da discussão pública só se mantém um simulacro, em que tudo é simbólico, até os próprios argumentos. A opinião pública é, então, uma ficção. O que há é um entrelaçado de opiniōes privadas, organizadas colectivamente. Na realidade, o discurso público é uma mera aparência e o compromisso de interesses obedece à lógica do equilíbrio de forças, não susceptível de racionalização. Habermas tira destes argumentos a conclusão de que há uma crise política de deslegitimitação e de desmotivação na nossa sociedade tardo-capitalista.

Tendo de concluir estas reflexōes sobre a Sociedade da Informação, convém fazer um recuo global e avaliar a situação à distância, segundo a proposta de Wolton. Sem dúvida que os sistemas de informação e de comunicação caracterizam a nossa sociedade e, como qualquer instrumento do homem, podem ser usados para o bem ou para o mal.

O perigo reside no modo como estão a ser usados que é o de uma perspectiva nominalista de que a filosofia da linguagem é paradigma. $O$ nominalismo é, desde os tempos de Filopónio e de Abelardo, uma das alternativas paralelas na historia da Filosofia. Os filósofos têm sabido ultrapassá-lo, recuperando os seus aspectos positivos, como sucedeu também com a Escola de Paris do séc. XIV.

O nominalismo actual começou com Descartes e Galileu que, na física, já foram ultrapassados pelas teorias contemporâneas. Devemos esperar que a filosofia actual encontre também uma via fecunda para o ultrapassar, na esteira de um Heidegger ou de um Husseri. 


\section{Considerações finais}

13. O conjunto dos actuais media, antigos e novos, constitui um sistema complexo que hoje está repleto de contradições, intimamente associadas às contradições da nossa própria sociedade que intensamente os utiliza. Justifica-se falar numa crise mediática, pelo menos no sentido utilizado por Blumler e Gurevitch, no seu estudo sobre a comunicação política. A crise é evidente no domínio político, mas tem também incidências nos domínios psico-social e socio-económico.

Wolton acredita que ainda é tempo de recuperar o domínio dos media pela sociedade, sendo a sua argumentação fundamentada nos valores da democracia europeia. $O$ seu melhor conselho consiste em recuperar o «distanciamento" face ao poder dos media. Mas este distanciamento face aos média só é possível no quadro de uma nova orientação do pensamento contemporâneo.

Como propõe Innerarity, há que procurar uma nova integração na unidade do mundo da vida, da ciência, da arte, da filosofia, da economia e da teoria política, contrariando o seu isolamento a partir do séc. XVI. O próprio projecto racionalista contém em si o duplo movimento de análise/síntese que não foi levado às ultimas consequências, sendo de facto a Ilustração um projecto inacabado. A síntese terá agora que ser feita, mas tal não será possível sem a adopção de uma perspectiva teleológica, baseada numa reavaliação dos valores clássicos.

\section{REFERÊNCIAS BIBLIOGRÁFICAS}

Blumer, Jay \& Gurevitch, Michael, The Crisis of Public Communication, Ed Routledge, London and New York, 1995.

Bougnoux, Daniel, Crise de I Information, Ed. La Doc. Française, «Prolémes p/s» 737, Paris, 1994.

InNERARITY, Daniel, Dialéctica de la modemidad, Ed. Rialp, Madrid, 1990.

Lochard, Guy \& Boyer, Henri, La Communication Mediatique, Ed Seuil Paris, 1998.

Wolton, Dominique, Penser la Communication, Ed. Flammarion, Paris, 1997. 